\title{
Introduction to JPART Virtual Issue on Citizen-State Interactions in Public Administration Research ${ }^{1}$
}

\author{
Morten Jakobsen, ${ }^{*}$ Oliver James, $†$ Donald Moynihan, $¥$ Tina Nabatchi $¥$ \\ * Aarhus University; † University of Exeter; ¥ University of Wisconsin-Madison; ¥¥ Syracuse University
}

\begin{abstract}
In this virtual issue, we bring together a collection of research articles that-although not usually grouped together-all illustrate the importance of citizen-state interactions. Specifically, we include articles that directly incorporate citizens' perceptions, attitudes, experiences of, or behavior related to public administration. About ten percent of all JPART articles over the life of the journal so far (1991-2015) met our inclusion criteria. Of those articles, we selected seven for this virtual issue on the basis that they have offered important insights into citizen-state interaction at different stages of the policy cycle. We argue that public administration scholarship should focus much more on the role of citizens and citizen-state interactions at all stages of the policy cycle. This research should focus both on the different forms of interaction citizens have with administrators, and the outcomes of these interactions, for bureaucracy and for citizens themselves.
\end{abstract}

\section{Citizens in Public Administration Research}

Politics and public administration rest on a series of interconnected relationships between different actors. These relationships are conventionally conceived of as a chain or

\footnotetext{
${ }^{1}$ Acknowledgements: We would like to thank Seunghui Samanta Lee, a doctoral student in the Social Sciences program at the Syracuse University Maxwell School of Citizenship and Public Affairs, for her assistance with this virtual issue.
} 
hierarchy of connections: from citizens to elected officials, elected officials to the bureaucracy, and, within bureaucracy to different administrative actors (varied by hierarchical or government level, organization, or sector) (Lynn, Heinrich, and Hill 2000). Such a model understates the degree to which the relationship between administrative actors and citizens suffuses all stages of the policy process. Beyond paying taxes and voting, citizens play several key roles in public administration. They participate in the design, production, and delivery of the public services they receive. They are the subjects of rules enforced by the state, and the ultimate evaluators of administrative outcomes.

Despite the critical importance of this link in public administration, citizen-state interactions have received relatively little direct attention within the field. Instead, scholars have tended to cast administrators in the largest roles on the public administration stage. An example of this tendency can be found in red tape research. Bozeman's (1993) canonical work offered a theoretical foundation that could be applied to the experiences of both citizens and administrative actors. But in the decades since its publication, researchers have focused almost entirely on managers' experiences of red tape, even though the colloquial understanding of the term evokes notions of citizen frustrations with the state.

Of course, citizens are represented, at least to some degree, in a few areas of public sector research, particularly on topics that carry weight with the authors of this introduction. For example, some of us have examined the role of performance information in democratic citizen-state interactions (James 2011b) and how expectations affect those interactions (James 2009; 2011a). Others have examined public participation, for example by examining the factors affecting coproduction (Jakobsen 2013), assessing how participatory designs might affect 
citizens' experiences in such processes (Nabatchi 2012), and exploring the myriad ways in which citizens can interact with administrators in various policy areas and governance levels (Nabatchi and Leighninger 2015). Still others have examined the impacts of administrative burdens on citizens' interactions with the state (Moynihan, Herd, and Harvey 2015). While we obviously believe there is merit to such work, we also acknowledge that it does not represent the totality of citizen experiences with government.

In an effort to more broadly capture and assess the scholarship on citizen-state interactions, we decided to create a virtual issue of JPART. We reviewed all JPART articles from the founding issue in 1991 to the final issue of 2015 - and were surprised to find that approximately ten percent examine some aspect of this subject. During our review, however, we were struck both by the lack of one or more foundational conceptual articles about citizenstate interactions and by the degree of fragmentation among relevant articles. Some might argue that these issues reflect a shift in JPART's focus from theoretical and conceptual work to sophisticated quantitative studies that focus on narrower administrative questions. We would disagree. JPART has published, and continues to publish, foundational papers on a wide variety of topics such as red tape, public service motivation, networks, organizational performance, and collaborative governance, which have a recognizable influence on research published in the journal (and elsewhere) today. Others might argue that work on citizen-state interactions requires tackling the "big questions" in public administration, an endeavor that does not align well with the ticking clocks of academic tenure and promotion processes (cf. Nabatchi, Goerdel, and Peffer 2011). This may be partly true; however, it does not fully capture the problem. 
We believe the absence of foundational articles and the fragmentation among relevant articles on citizen-state interaction are attributable to two problems: a path-dependent focus on administrative actors, and the more fundamental problem of theorizing about the role of citizens.

It is often challenging to identify areas of public administration research that specifically and directly focus on citizens. Why is this the case? Habit, path-dependency, and convenience play a role. As researchers focus on bureaucrats and third-sector leaders as the operators of administrative machinery, the concerns of citizens are pushed to the background. The primary datasets to which PhD students have access largely center on the experiences of administrative actors, and much of what students read in journals centers on how to better study these actors. The idea that citizen-state interactions offer a venue to study the functioning of the state is not strongly communicated. To the degree these interactions are contemplated, they are relegated to specialized sub-topics, such as street level bureaucracy, representative bureaucracy, or citizen participation. For the researcher, it has been easier to add a battery of previously tested questions on bureaucratic experiences to a survey of administrators rather than to develop new questions and concepts related to citizen experiences, or to find ways to access and survey citizens. There are, however, reasons to be optimistic about studying citizen-state interactions. Methods continue to evolve, creating new ways to tap into citizen experiences and making data collection easier. For example, crowdsourced internet marketplaces, including Mechanical Turk, and other online data collection tools offer novel ways to generate survey and experimental data. Open data initiatives around the world are creating growing possibilities for using extant administrative information about how citizens interact with government. 
The second problem is perhaps more challenging, which is how to theorize the concept of "citizen-state interaction." As noted above, citizens interact with the state - and the state interacts with citizens - in many and varied ways. The scope and varieties of such interactions mean that relevant and related research often does not share the common touchstones, assumptions, or language found in other areas of public administration such as networks, performance, or public service motivation. Thus, though perhaps working on related issues, researchers studying citizen-state interactions often talk past each other. Not only does this situation make it difficult to accumulate knowledge, it also has troubling concomitant impacts on the possibilities for theory development. Of course, we recognize that a single grand theory of citizen-state interactions is highly unlikely (particularly within the confines of journal article page limits) and perhaps even undesirable if it narrows conceptualization. However, even if the breadth of the topic limits possibilities for such theoretical development, the depth achieved by scholars examining some of the constituent parts of citizen-state interactions does make it possible to work toward an overarching framework that categorizes and specifies aspects of citizen-state interactions.

This view shaped our construction of this virtual issue. Specifically, we wanted to bring together articles that-in spite of having a common focus on citizens-are not usually highlighted or grouped together. Thus, we sought out pieces that capture the myriad ways in which citizens interact with the state, be it as voters, taxpayers, clients, customers, or participants. We then used the stages of the policy cycle as a simple heuristic for categorizing articles. For purposes of simplicity, we break the policy cycle into three stages: design, implementation and service delivery, and evaluation. We acknowledge that policy does not 
always proceed in this way and that there are complex feedback mechanisms across stages.

However, this simple model immediately helps us to organize recognizable streams of research on citizen-state interactions (see Figure 1). For example, studies of public participation, rulemaking, and citizens' attitudes about, perceptions of, and expectations for the state often focus on how citizens engage in policy design. Studies of coproduction, administrative burdens, corruption, and rule compliance inform the implementation and delivery stage. Studies of citizen satisfaction, administrative performance, and trust in government and political voice are relevant to the evaluation stage. But while such subtopics exist, the consequence of a lack of an overarching framework is that common interests across these subtopics are easily overlooked and are uninformed by the sharing of collective insights. Thus, while this model may be incomplete or overly simplistic, it nevertheless invites debate and improvement, requiring only that future scholars take the concept of citizen-state interactions as a central organizing principle.

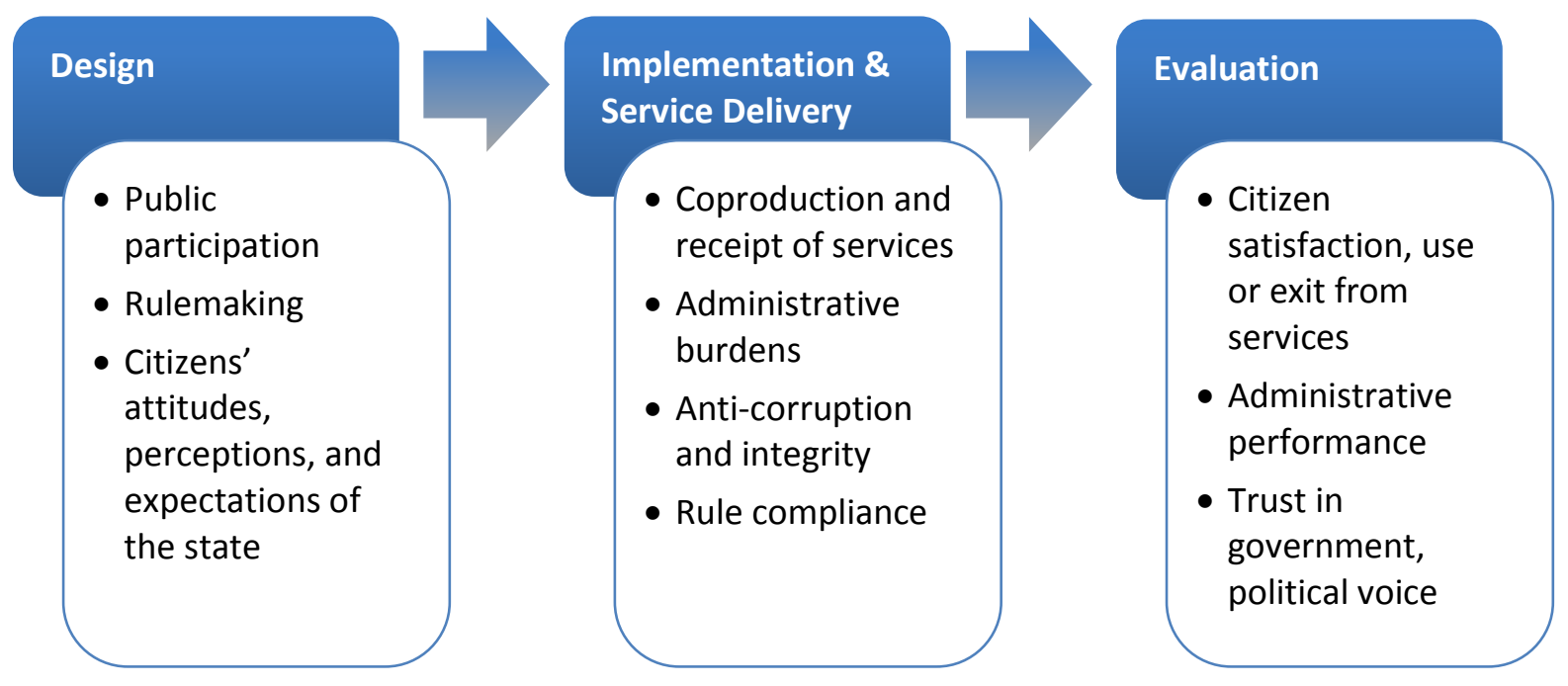

Figure 1. Stages of the Policy Cycle and Citizen State Interactions

\section{Article Selection}


Our guiding principle for article selection was to look for work that directly incorporates citizens' experiences of administration in some stage of the policy cycle, with the goal of having at least one article for each stage. Regarding the policy design stage, we reviewed articles that examine topics such as citizen participation in policy formulation and administrative planning. In the implementation and service delivery stage, we reviewed articles that explore citizeninitiated contacts, administrative burdens, coproduction, and related issues. Finally, in the evaluation stage, we reviewed work on citizen satisfaction, citizens' reactions to performance information, citizens' trust in government, and citizens' ability to hold the administration accountable, among other issues.

As noted above, the co-editors have a broad set of interests in the role of citizens in public administration; however, for impartiality, we excluded from consideration our own work published in JPART. Moreover, given that the focus of the virtual issue is on citizens' experiences of administration, we excluded work on topics such as representative bureaucracy, street-level bureaucrats, public-private partnerships, and administrative responsiveness, which tends to focus on the administrative side of the citizen-administration interaction. Through this initial review process, we identified sixty relevant articles. Figure 2 shows the absolute distribution of the relevant articles from 1991 to 2015. The bars show the absolute number of citizen-state articles per year. The line (created with a LOWESS function) shows the share of citizen-state articles per year and suggests a modest positive trend over time. 


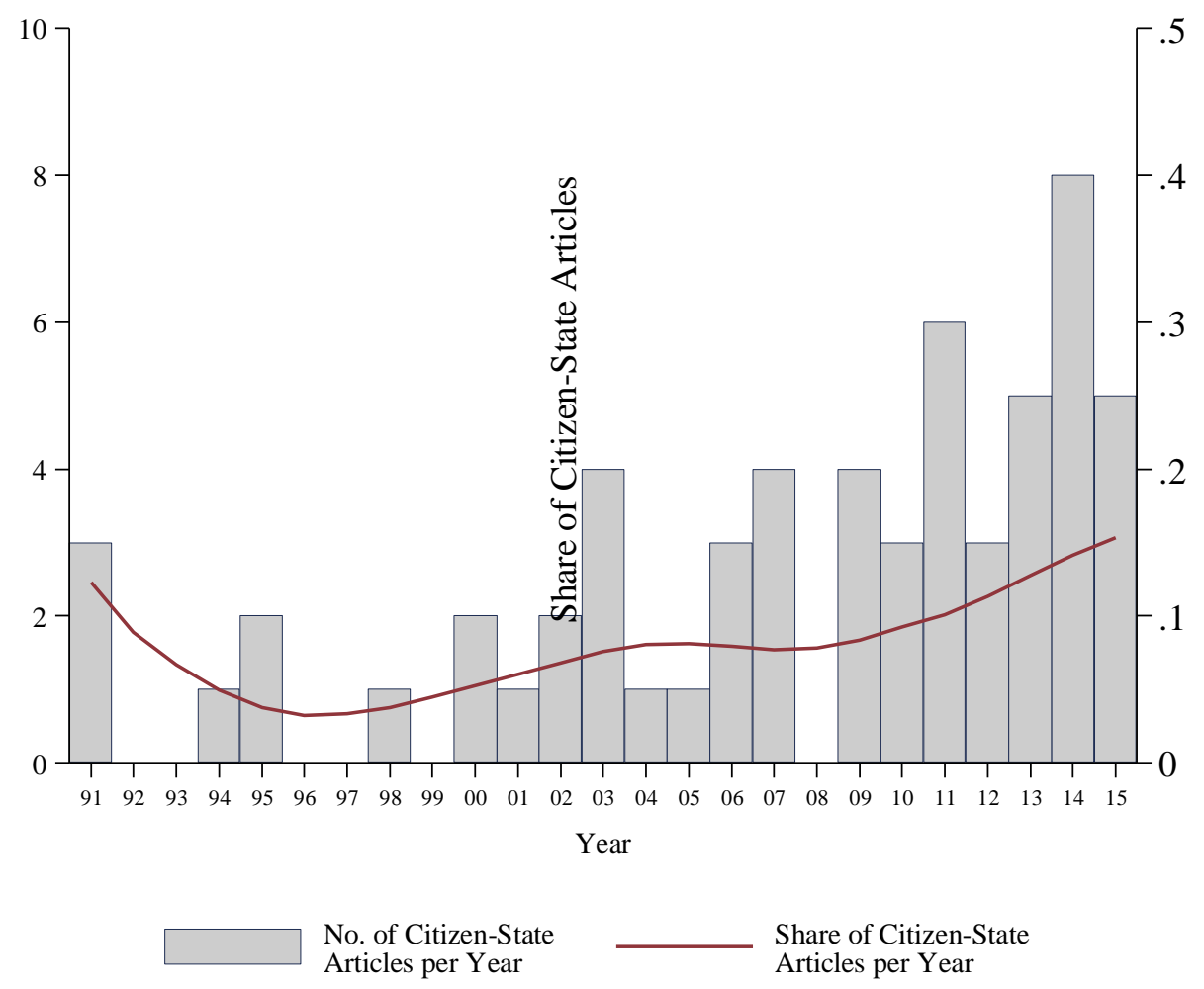

Figure 2. Distribution of JPART Articles with a Citizen Perspective, 1991-2015.

To narrow down the sixty articles, we first categorized them according to where each fell in the policy cycle. We dropped articles published between 2013 and 2015, which have not yet had enough time to demonstrate their contribution. Part of our assessment was undoubtedly subjective: some papers were especially timely in anticipating and foreshadowing later work, even if one could argue that later work more comprehensively addressed the question. Other work reflected a skillful empirical illustration of how abstract ideas could illuminate an applied topic. Following this iterative winnowing process, we selected seven articles to be included in this virtual issue. The articles included in the virtual issue are marked with an asterisk $(*)$ in the reference list. 
It should be noted that we were forced to leave out many excellent and important articles; we encourage readers to dive into JPART issues to better understand the breadth and depth of scholarship on citizen-state interactions, including many of the articles cited in this introduction. Figure 3 shows where each of the seven articles falls in the policy cycle. Six of the articles, at least to a certain extent, can be categorized within the three stages of the policy cycle we identified; however, one article (Thomas and Streib 2003) spans all of the stages. We organize our discussion of the articles into subsections focused on the stages of the policy cycle. For each stage, we briefly explore the included articles and assess how they fit within the theme of citizen-state interactions. Given its cross-stage applications, we examine Thomas and Streib's (2003) article separately, in the final subsection.

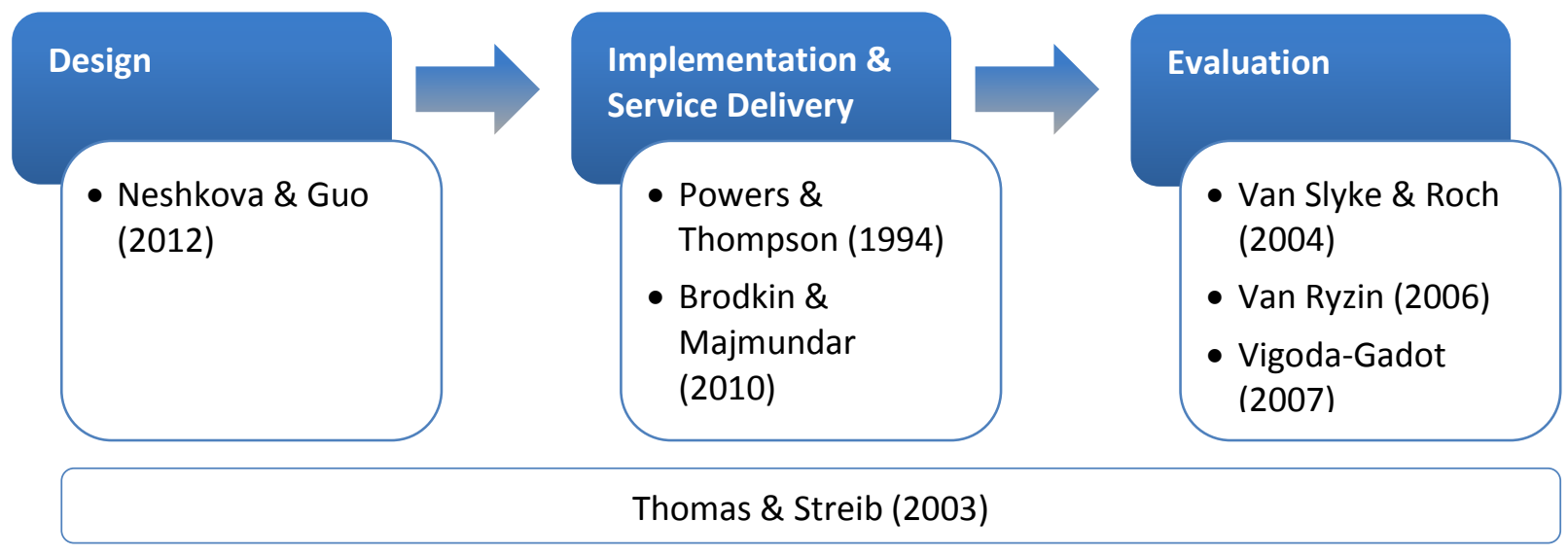

Figure 3. Selected JPART Articles Categorized by Stage of Policy Cycle

\section{The Design Stage: The Opportunities and Effects of Participation}

The use of public participation, which we associate with the design stage of the public policy cycle, has been the topic of much research. While most studies focus on specific cases of 
participation, best practices, or conceptual and normative issues, Neshkova and Guo (2012) seek to understand public participation in the context of a core function of public administration - the efficient and effective delivery of public services. Specifically, they examine the extent to which public managers use participation to set budget priorities and whether participation affects the efficacy and effectiveness of organizational performance. Although advocates claim many benefits of public participation, including its ability to improve organizational and policy or service outcomes, empirically demonstrating those benefits has been notoriously difficult because of data availability and methodological issues.

Neshkova and Guo overcome these obstacles with a creative use of Government Performance Project (GPP) data. Specifically, they use pooled GPP data from three years (20032005) and focus on the responses of 39 state Departments of Transportation, which gives them a total of 117 cases for analysis. Drawing information from the financial management section of the survey, they identify (a) the strategies used for collecting input from citizens on budget priorities, and (b) the stages in the budgeting process where these strategies are used. They couple these data with information from the Bureau of Transportation Statistics, which is used to construct measures of organizational efficiency and organization effectiveness, along with several control variables. Finally, they use a panel corrected standard error model to estimate the effects of citizen participation, task difficulty, and program resources on organizational efficiency and effectiveness.

Their results show that citizen input is positively and significantly associated with better service in terms of both efficiency and effectiveness. Specifically, all else equal, more public participation is associated with fewer expenditures per vehicle mile traveled (a measure of 
organizational efficiency) and with fewer poor quality roads and lower highway fatality rates (measures of organizational effectiveness). These findings provide strong support for the claim that public participation leads to enhanced organizational performance: public agencies can become more efficient and effective by seeking greater input from the public and incorporating it in their decision making. For advocates of participation, these findings should be particularly salient, as they enable the justification of participation not only in normative terms, but also in instrumental terms; that is, participation does not just generate normative social value, but also can enhance public program performance and public service provision (cf. Moynihan 2003). Time will tell whether other scholars are also able to creatively use or generate data to offer further empirical evidence about the impacts of participation on organizational performance, but also on other citizen effects, such as political efficacy or involvement.

\section{Implementation and Service Delivery: How do Citizens Co-Produce and Receive Services}

In the service delivery phase, Powers and Thompson's (1994) article concerns citizen coproduction of public services. Specifically, the article provides an early contribution to identifying the factors that affect citizens' input to service production and what public administration can do to help. Thus, it not only builds on the concept of coproduction and arguments about the importance of citizen input to service delivery, first articulated in the late 1970s and early 1980s (e.g., Brudney and England 1983; Ostrom 1972; Parks et al. 1981), but also moves toward an assessment of how citizens' input may be increased and maintained. Specifically, Powers and Thompson use expectancy theory to argue that for citizens to contribute input to the production of public services, citizens must have a clear idea about what is expected from them in the production process, and the ability and proper incentives to meet 
those expectations. Additionally, Powers and Thompson (1994) outline arguments about how public administration may organize and implement services to optimally structure such expectations, abilities, and incentives. In particular, they focus on how to overcome free rider problems when attempting to foster citizen coproduction.

While Powers and Thompson's (1994) article mostly consists of a theoretical discussion, others have built on this work with empirical examinations. For example, Bifulco and Ladd (2006) examine how institutional arrangements (in their case, decentralization of authority) affect citizens' contributions to service production. In recent years, a number of studies have continued to develop arguments about how administration can enhance citizen coproduction. Jakobsen (2013) focuses on how government initiatives to provide citizens with knowledge and materials may increase coproduction, and Thomas (2013) uses the existing theory and empirical studies to develop more practical guidelines for citizen-public employee interactions in coproduction.

Brodkin and Majmundar's (2010) study captures both the administrative burdens citizens' experience in the implementation of public services and the implications of those burdens for receipt of services and equity. They revisit one of the most debated chapters in the history of the modern welfare state: the decline in welfare caseloads after the reorganization of welfare provision in the United States in the mid-1990s. This decline was championed in some quarters as an illustration that the state could change bureaucratic and citizen incentives to generate better outcomes: in effect, elected officials could act as master designers to restructure citizen-state interactions to a more productive relationship. 
Brodkin and Majmundar challenge this claim by showing that a good deal of the decline of caseloads arose because of procedural barriers that citizens encountered in the new welfare system. Patterns of administrative exclusion appeared to be more prominent after the first round of welfare reductions took place, suggesting a strategic use of administrative burdens to exclude citizens when the most employable welfare beneficiaries had left the system. Just as troubling, Brodkin and Majmundar suggest that administrative barriers will be more problematic for some groups than others, and find that those with lower education seem to be less able to overcome these barriers and access social services. In another JPART paper, Keiser and Miller (2010) point to the importance of social supports as a means of overcoming burdens, finding that military veterans were more likely to work their way through administrative barriers if they lived in a state with an active veteran groups that could help them negotiate the process.

One implication of Brodkin and Majmundar for citizen-state interactions is that the myth of the state as a master designer of these relationships gives way instead to a messier reality of citizens struggling to manage new and demanding burdens placed upon them. Moynihan, Herd, and Harvey (2015) argue that uncovering the construction, nature, and impacts of administrative burdens should be a central task of public administration. Accordingly, they propose that in some cases, the deployment of administrative burdens is a strategic extension of politics, used to target policies and citizens that politicians oppose. Heinrich (2015) also draws upon Brodkin and Majmundar to suggest that administrative burdens are present - and perhaps even more prominent - in poorer countries, such as the South African setting she studies. She finds that cash payment systems are frequently delayed by the haphazard 
implementation of such burdens and the difficulties poorer citizens face in providing

documentation. Not only do citizens lose out on much-needed services, but the policy goals of programs become undercut as they fail to reach their intended recipients.

\section{The Evaluation Stage: Sorting Through Citizens Beliefs About Administration}

Van Slyke and Roch's (2004) article is an early attempt to explore how citizens evaluate services in a context where service delivery has been blurred between sectors. The paper both anticipates concerns about accountability and basic citizen comprehension of public services under the "submerged state" (Mettler 2011) and extends those concerns to service delivery. Specifically, Van Slyke and Roch (2004: 192) seek to assess citizens' "ability to hold governmental and nonprofit organizations accountable for the quality of the services they receive." The structure of the research design is deceptively simple: the authors survey recipients of social services, focusing on those who said they had contact with social services organizations. They find that individuals were more likely to report a positive experience with social services when they believed those services were delivered by a non-profit. This subjective belief of citizens is important, because Van Slyke and Roch find that citizens regularly confuse public and non-profit providers, which suggests that citizens may not be well-informed service consumers. Perhaps more troubling is the finding that citizen confusion was not randomly distributed. Instead, citizens tended to believe they were served by non-profits if the service was positive, and more likely to (wrongly) attribute negative experiences to being served by a public organization.

Recent experimental work by Marvel (2016) offers support for Van Slyke and Roch's claims, suggesting that citizens have an unconscious bias against publicly-provided services, 
assuming that such services are of poorer quality than those provided by non-public rivals. This central insight of Van Slyke and Roch points to two fundamental difficulties in considering citizen evaluations of services for accountability purposes. First, in a blurred service delivery environment, citizens struggle to identify what is public and what is not. Second, they tend to not evaluate public and non-public services in the same way. In pointing to the practical implications of their work, Van Slyke and Roch urge public managers to better "brand" public services, a recommendation that anticipated the relevance of organizational reputation and branding more generally (e.g., Maor and Sulitzeanu-Kenan 2016).

Van Ryzin's (2006) article goes even further in correcting the naïve view that management can raise citizen satisfaction simply by improving performance - satisfaction is affected both by citizens' expectations and by performance levels. Specifically, his research finds that subtractive disconfirmation (performance minus expectations) is positively related to satisfaction. Put another way: two citizens with different prior expectations could experience the same level of organizational performance quite differently.

Van Ryzin's early work on this issue has spawned a considerable amount of research focused on the expectations disconfirmation model (see also Van Ryzin 2013). For example, James (2009) shows that citizens' normative expectations about performance matter greatly to their ultimate satisfaction, and that high satisfaction with services could actually reflect low expectations rather than good performance. In their observational study, Poister and Thomas (2011) also find support for the main hypotheses of the expectations disconfirmation model. Experimental research shows that information about the quality of performance shifts citizens' perceptions of performance and their satisfaction with services, which has implications for 
whether they lend political support to those responsible for provision (James 2011b).

Experiments giving citizens performance information show that such information shifts citizens' positive expectations of what service quality will be, but not their normative expectations of what it should be, suggesting that the management of normative performance expectations to try to raise citizen satisfaction is not always possible (James 2011a).

Vigoda-Gadot (2007) takes a different approach to examining citizens' evaluations of public organizations, concentrating on their perceptions of organizational politics and ethics. This work draws on ideas from management theory and broader political science theory about societal political attitudes and behavior (Almond and Verba 1965). The empirical part of the study, informed by national surveys, finds that these perceptions shape both satisfaction with services and trust in governmental institutions. Moreover, perceptions and attitudes about organizational politics and ethics affect the public's voice orientations and actions, including political efficacy and political participation. Together, these findings show that citizen evaluations feed back into support (or lack of support) for policy and its implementation. This research adds further support to findings about how trust in government can affect whether societies will pay collectively for public programs (Hetherington 2005) and how trust can influence citizens' willingness to comply with rules (Tyler 1990).

Furthermore, Vigoda-Gadot's findings suggest that citizens' perceptions of fairness and a lack of predatory organizational politics contribute to broader outcomes, such as social peace and the perceived legitimacy of public institutions in democratic societies. These findings have influenced subsequent studies. For example, scholars have examined the relationship between citizen attitudes towards democratic institutions and bureaucracy in a set of European 
countries (Vigoda-Gadot, Shoham, and Vashdi 2010). The findings have also been extended to the context of new technological developments in citizen-state interactions, where research has shown a positive association between participants' assessment of e-government, transparency, and trust in the local government that provided the program (Kim and Lee 2012).

\section{Spanning the Policy Stages: Citizen Voice in Governmental Activities}

One of our selected articles, Thomas and Streib (2003), is relevant in all stages of the policy cycle, as it focuses on citizen-initiated contacts with administration. This topic has a long history in public administration research given the normative and instrumental importance of citizen voice to government functioning (e.g., Jones et al. 1977). Indeed, as suggested throughout this introduction to the virtual issue, there is general agreement that government activities benefit when citizens are afforded the opportunity to contribute to policy design and planning, service delivery and implementation, and evaluation.

Previous studies on this topic focus on which citizens initiate contact with administrative actors, as well as how and why they initiate contact (e.g., Thomas and Melkers 1999). However, Thomas and Streib's (2003) article is one of the first to examine how the internet impacted citizen-initiated contacts with public administration actors and agencies. Specifically, they examine how often citizens use the internet to contact the administration, how citizens evaluate government websites, and which citizens tend to contact the administration via the internet. They find a substantial lack of representativeness among visitors to government websites, echoing a long-standing problem with other forms of participation (Moynihan 2003). Moreover, they find that website users were more likely to be white, better educated, wealthier, and younger than internet users in general. 
Although this research took place in the early days of the internet, it was among the first to map the impacts of the internet on the changing terrain of citizen-state interactions. Moreover, it laid the groundwork for and inspired numerous future studies that focus on how technology is contributing to the evolution of citizen-state interactions. While some of the findings may no longer hold, others are perhaps still relevant to our understanding of the digital divide in relation to citizen-initiated contact with government.

\section{Conclusion}

Together, the seven articles featured in this virtual issue contribute to the knowledgebase in public administration about citizen-state interactions. Of course, these articles do not capture the full breath of the concept (perhaps no set of articles could); however, they are representative of some of the aspects or constituent parts of this complex subject. Moreover, they have been (and we expect will continue to be) influential in shaping research agendas on citizen-state interactions in public administration.

In an effort to spark ongoing dialogue and encourage more research on this topic, we leave readers with five interrelated points. First, it is perhaps unreasonable to expect the development of a grand theory about citizen-state interaction in public administration. The topic is simply too broad, and the many diverse applications across the policy cycle do not lend themselves to such efforts. Second, in the absence of a grand theory, the scholarly tool that might best facilitate progress in this area is a conceptual framework that do not necessarily seek to explain outcomes, but instead to categorize related work under a common theme. Such a framework can help to generate researchers identify shared reference points, language and assumptions, but also help the casual reader to understand how the citizen plays a role in 
governance. We offer the stages of the policy process as a guiding framework, but encourage scholars to develop and offer other frameworks that enable better communication across boundaries. Third, it is possible to identify some of the constituent parts of citizen-state interactions. Indeed, our review of JPART and other articles shows that scholars have been generating theoretically-informed empirical work addressing relevant and related topics for decades. Fourth, there is clearly room for more research (theoretical, conceptual, and empirical) on citizen-state interactions. To make significant progress on the overall topic, however, researchers need to stretch beyond the immediately apparent boundaries of their specific subject matter to connect to the broader array of research on the topic. Finally, and perhaps most important, the notion of citizen-state interactions is a legitimate and valuable form of public administration research, and should be seen as such. We hope that other scholars will agree with this conclusion and that such work will become central in our field. Accordingly, we expect that the next 25 years of JPART will provide an even richer array of research on citizen-state interactions.

\section{References}

The seven articles included in the virtual issue are marked with an asterisk $\left({ }^{*}\right)$.

Almond, Gabriel A., and Sydney Verba. 1965. The Civic Culture: Political Attitudes and Democracy in Five Nations: An Analytic Study. Boston, MA: Little, Brown.

Bifulco, R. and H. F. Ladd. 2006. Institutional Change and Coproduction of Public Services: The Effect of Charter Schools on Parental Involvement. Journal of Public Administration Research and Theory, 16(4): 553-576.

Bozeman, B. 1993. A Theory of Government "Red Tape." Journal of Public Administration Research and Theory, 3(3): 273-304. 
* Brodkin, E. Z. and M. Majmundar. 2010. Administrative Exclusion: Organizations and the Hidden Costs of Welfare Claiming. Journal of Public Administration Research and Theory, 20(4): 827-848.

Brudney, J. L. and R. England. 1983. Toward a Definition of the Co-Production Concept. Public Administration Review, 43(1): 59-65.

Heinrich, C. J. 2015. The Bite of Administrative Burden: A Theoretical and Empirical Investigation. Journal of Public Administration Research and Theory, doi: 10.1093/jopart/muv034.

Hetherington, M. J. 2005. Why Trust Matters: Declining Political Trust and the Demise of American Liberalism. Princeton, NJ: Woodstock: Princeton University Press.

Jakobsen, M. 2013. Can Government Initiatives Increase Citizen Coproduction? Results of a Randomized Field Experiment. Journal of Public Administration Research and Theory, 23(1): 27-54.

James, O., 2009. Evaluating the Expectations: Disconfirmation and Expectations Anchoring Approaches to Citizen Satisfaction with Local Public Services. Journal of Public Administration Research and Theory, 19(1): 107-123.

James, O., 2011a. Managing Citizens' Expectations of Public Service Performance: Evidence from Observation and Experimentation in Local Government. Public Administration, 89(4): 1419-1435.

James, O. 2011b. Performance Measures and Democracy: Information Effects on Citizens in Field and Laboratory Experiments. Journal of Public Administration Research and Theory, 21(3): 399-418.

Jones, B. D., S. R. Greenberg, C. Kaufman, and J. Drew. 1977. Bureaucratic Response to CitizenInitiated Contacts: Environmental Enforcement in Detroit. The American Political Science Review, 71(1): 148-165.

Keiser, L. R. and S. M. Miller. 2010. The Impact of Interest Groups on Eligibility Determination: The Case of Veterans' Disability Compensation. Journal of Public Administration Research and Theory, 20(2): 505-531.

Kim, S. and Lee, J., 2012. E-Participation, Transparency, and Trust in Local Government. Public Administration Review, 72(6): 819-828.

Lynn, L. E., C. J. Heinrich, and C. J. Hill. 2000. Studying Governance and Public Management: Challenges and Prospects. Journal of Public Administration Research and Theory, 10(2): 233-262. 
Maor, M. and R. Sulitzeanu-Kenan. 2016. Responsive Change: Agency Output Response to Reputational Threats. Journal of Public Administration Research and Theory, doi:10.1093/jopart/muv001.

Marvel, J. D. 2016. Unconscious Bias in Citizens' Evaluations of Public Sector Performance. Journal of Public Administration Research and Theory, 26(1): 143-158.

Mettler, S. 2011. The Submerged State: How Invisible Government Policies Undermine American Democracy. Chicago, IL: University of Chicago Press.

Moynihan, D. P. 2003. Normative and Instrumental Perspectives on Public Participation: Citizen Summits in Washington D.C. American Review of Public Administration, 33(2): 164-188.

Moynihan, D. P., P. Herd, and H. Harvey. 2015. Administrative Burdens: Learning, Psychological and Compliance Costs in Citizen-State Interactions. Journal of Public Administration Research and Theory, 25(1): 43-69.

Nabatchi, T. 2012. Putting the 'Public' Back in Public Values Research: Designing Public Participation to Identify and Respond to Public Values. Public Administration Review, 72(5): 699-708.

Nabatchi, T., H. T. Goerdel, and Shelly Peffer. 2011. Public Administration in Dark Times: Some Questions for the Future of the Field. Journal of Public Administration Research and Theory, 21(suppl 1): i29-i43.

Nabatchi, T. and M. Leighninger. 2015. Public Participation for $21^{\text {st }}$ Century Democracy. San Francisco, CA: Jossey-Bass.

* Neshkova, M. I. and H. Guo. 2012. Public Participation and Organizational Performance: Evidence from State Agencies. Journal of Public Administration Research and Theory, 22(2): 267-288.

Ostrom, E. 1972. Metropolitan Reform: Propositions Derived from Two Traditions. Social Science Quarterly, 53(4): 474-493.

Parks, R. B., et al. 1981. Consumers as Coproducers of Public Services: Some Economic and Institutional Considerations. Policy Studies Journal, 9(7): 1001-1011.

Poister, T. H. and Thomas, J. C. 2011. The Effect of Expectations and Expectancy Confirmation/ Disconfirmation on Motorists' Satisfaction with State Highways. Journal of Public Administration Research and Theory, 21(4): 601-617.

* Powers, K. J. and R. Thompson. 1994. Managing Coprovision: Using Expectancy Theory to Overcome the Free-Rider Problem. Journal of Public Administration Research and Theory, 4(2): 179-196. 
Thomas, J. C. 2013. Citizen, Customer, Partner: Rethinking the Place of the Public in Public Management. Public Administration Review, 73(6): 786-796.

* Thomas, J. C. and G. Streib. 2003. The New Face of Government: Citizen-Initiated Contacts in the Era of E-Government. Journal of Public Administration Research and Theory, 13(1): 83-102.

Thomas, J. C. and J. Melkers. 1999. "Explaining Citizen-Initiated Contacts with Municipal Bureaucrats: Lessons from the Atlanta Experience" Urban Affairs Review, 34(5): 667690.

Tyler, T. R. 1990. Why People Obey the Law. New Haven, CT: Yale University Press.

* Van Ryzin, G. G. 2006. Testing the Expectancy Disconfirmation Model of Citizen Satisfaction with Local Government. Journal of Public Administration Research and Theory, 16(4): 599611.

Van Ryzin, G. G. 2013. An Experimental Test of the Expectancy-Disconfirmation Theory of Citizen Satisfaction. Journal of Policy Analysis and Management, 32(3): 597-614.

* Van Slyke, D. M. and C. H. Roch. 2004. What Do They Know, and Whom Do They Hold Accountable? Citizens in the Government-Nonprofit Contracting Relationship. Journal of Public Administration Research and Theory, 14(2): 191-209.

* Vigoda-Gadot, E. 2007. Citizens' Perceptions of Politics and Ethics in Public Administration: A Five-Year National Study of Their Relationship to Satisfaction with Services, Trust in Governance, and Voice Orientations. Journal of Public Administration Research and Theory, 17(2): 285-305.

Vigoda-Gadot, E., A. Shoham, and D. R. Vashdi. 2010. Bridging Bureaucracy and Democracy in Europe: A Comparative Study of Perceived Managerial Excellence, Satisfaction with Public Services, and Trust in Governance. European Union Politics, 11(2): 289-308. 